\title{
İplik Sürtünme Özelliklerinin İncelemesinde Kaba Kümeler Yaklaşımı
}

\section{Caner ERDEN ${ }^{*}$, Mahmadjon NAZAROV ${ }^{2}$}

${ }^{1}$ Sakarya Üniversitesi, Esentepe Kampüsü (Endüstri Mühendisliği, Sakarya Üniversitesi, Sakarya, Türkiye)

${ }^{2}$ İstanbul Üniversitesi, Avcılar Kampüsü (Endüstri Mühendisliği, İstanbul Üniversitesi, İstanbul, Türkiye)

(Geliş Tarihi/Received: 03.12.2015, Kabul Tarihi/Accepted: 01.02.2016)

\section{ÖZET}

Bu çalışmada Kaba kümeler teorisi kullanılarak ipliklerin sürtünme özelliklerinin analiz edilmesi amaçlanmıştır. Çalışmada kullanılan 10 örnek veri seti gerçek verilerdir. Sürtünme özelliği olan $\mu$ ipliğin 4 özelliği tarafından belirlenmiştir. Bu özellikler; iplik numarası, hammadde, büküm sayısı ve üretim teknolojisi özellikleridir. Bu karar sisteminde 4 özellik sınıfı ve 1 karar sınıfı bulunmaktadır. İpliklerin sürtünme özelliklerini analiz etmek için Kaba kümeler teorisi için ayarlanmış olan ROSE2 (Rough Sets Data Explorer) yazılımı kullanılmıştır. Bu çalışma sonucunda hammadde özellik sınıfının iplik sürtünme özellikler arasındaki en önemli özellik olduğu sonucuna varılmıştır.

Anahtar kelimeler: İplik, İplik Sürtünme Özellikleri, Kaba Kümeler Teorisi, ROSE2

\section{Rough Sets Approach in Analysis of Yarn Friction Properties}

\begin{abstract}
This paper was intended to analyze the frictional properties of yarns using Rough sets theory. Ten examples are investigated in this paper. The data used in this study are real data. The frictional properties $(\mu)$ of yarn samples determined in respect of four features of yarn. These features are; yarn count, raw material, twist level and production technology. One decision variable and four attributes are used as information system. ROSE2 (Rough Sets Data Explorer) software implemented to the data set to analyze the frictional properties of yarns. As a conclusion, we concluded that raw material has the leading impact on frictional properties of yarn.
\end{abstract}

Keywords: Yarn, Friction Properties of Yarn, Rough Sets Theory, ROSE2

\section{Giriş}

Sürtünme kuvvetinin varlı̆̆ veya liflerden eğrilen ipliklerdeki lifler arası yokluğu tekstil teknolojisinde çok önemli rol kohezyonu ve dolayısıyla iplik mukavemetini oynamaktadır. Tekstil sanayisinde iplik etkilemektedir. Ayrıca bu sürtünme, lif ve üretiminin çeşitli aşamalarında, liflerin ipliklerin hareketi sırasında oluşan paralel hale getirilmesi ve liflerin bir düzen gerilimleri, çeşitli tekstil makinelerindeki içinde hareket ettirilmeleri, lifler arasındaki kılavuzların aşınmasını, kumaşlardaki yüzey sürtünme kuvvetleri sayesinde olmaktadır. düzgünsüzlük olasılıklarını ve kumaşın Lifler arasındaki sürtünme; lif gruplarının tutumunu da etkilemektedir. Tekstil çekim işlemi sırasındaki davranışını, kesikli endüstrisinde kumaşın sürtünmeye karşı 
dayanımı; kumaşın zamanla yıpranması nedeniyle kötü görünmesi ve giysilerin kullanma süresinin kısalması nedeniyle çok önemlidir. Bir tekstil kumaşında; liflerin ipliğe, ipliklerin de dokuma veya örme kumaşa dönüşmesi, lif-lif ve iplik-iplik sürtünme kuvvetleri sayesinde gerçekleşebilir. Bu nedenle lif veya iplikler arasındaki sürtünme hem iplik üretiminde hem de kumaş üretiminde kaliteyi etkileyen en önemli faktörlerden biridir. Kumaşların yumuşaklığı, pürüzlülüğü, boncuklanma oluşumu, aşınma ve giyim dayanımı gibi özellikleri sürtünme ile doğrudan ilişkilidir (Balcıl ve Sülar, 2016). İplik üretiminde iplik genellikle metal, seramik ya da başka yüzeyler üzerinde taşınır ve bu çalışma yüzeyleri ile iplik arasında bir sürtünme meydana gelir. Literatürdeki çalışmalara bakıldığında genellikle sürtünmeden kasıt, sürtünmenin lifler arasında gerçekleştiği durumlardır (Morton ve Hearle, 1962; Varža, 1981; Denby ve Andrews, 1965) . Tekstil kumaşlarının hem kalitesini belirlemede hem de verimliliğini etkilemekte önemli bir role sahip olan iplik sürtünmesi; lif özellikleri, iplik özellikleri, işlem parametreleri ve bitim işlemleri olarak sinıflandırılabilecek birçok faktörden etkilenmektedir. Bu nedenlerden dolayı iplik sürtünme özelliğinin araştırılması çok büyük bir öneme sahiptir (Svetnickienė ve Čiukas, 2006). Hong, 2000 yllında yaptığı çalışmada; iplik sürtünme özelliklerini etkileyen faktörleri 4 ana başlık altında toplamıştır. Bu sınıflandırmada, ana sınıflar; lif özellikleri, iplik yapısı ve hacimsel özellikler, işlem parametreleri ve bitim işlemleri olarak tanımlanmıştır (Hong, 2000). Bu sinıfların dışında; iplik sürtünmesi, büküm açısı, sürtünmenin düzgünlüğü ve sıcaklığı, iplik bükümü, yüzey yağlılı̆̆ı, hareket hızı, iplik pürüzlülüğü, havlılık ve elektrik özellikleri gibi faktörlerden etkilenmektedir (Matukonis, ve diğ., 1976; Morton ve Hearle, 1962; Wegener ve Shuler, 1964; Pažarauskas, 1992).

Yapılan çalışmalar iplik sürtünme özelliğini etkileyen sadece bir faktör olmayacağını göstermiştir. İplik kalitesini gösteren en önemli faktörlerden biri olan iplik numarası, iplik hakkında bilgi edinmek için kullanılan birincil özelliklerden birisidir. $\mathrm{Bu}$ özellik ipliğin kalitesini doğrudan etkilemekte ve iplik sürtünmesinin oluşmasında da çok önemli bir role sahiptir (Gupta, 2008). Kalyanaraman, iplik numarasının sürtünme özelliği üzerindeki etkisini ortaya koymak için yaptığı çalışmada SITRA sürtünme ölçüm cihazı ile ölçüm yaparak ipliğin lineer yoğunluğunun artırılmasıyla sürtünme katsayısının arttığını gözlemlemiştir (Kalyanaraman, 1988).

Sürtünmeyi etkileyen bir diğer özellik ise hammadde özelliğidir. İpliğin hammaddesi pamuk, yün ya da viskoz vb. farklı liflerden oluşabilir. Bu liflerin iplik sürtünmesine yaptığı etkiyi göstermesi açısından birçok çalışma yapılmıştır. Bu çalışmalardan birisine sahip olan Ajayi ve Elder 1994 yılında yaptıkları çalışmada en yüksek sürtünme katsayısına sahip hammadde türünün yün, en düşük olanın ise akrilik lifi olduğunu göstermişlerdir. $\mathrm{Bu}$ çalışma için 4 farklı hammaddeden üretilmiş 
iplik türü kullanılmıştır. Bunlardan; doğal bağlı olarak incelemişlerdir. Yapılan olanları pamuk ve yün, rejenere olanı viskoz ve sentetik olanı akrilik lifidir. (Ajayi ve Elder, 1994). Hammadde özellikleri için yapılan birçok çalışma bulunmaktadır (Rankumar, ve diğ., 2003; Svetnickienè ve Čiukas, 2006; Schick, 1973). Gupta ve El Mogazhy liflerin moleküler oryantasyonunun akrilik ipliğine etkisini araştırmışlar. Yapılan araştırmada; lifler arası sürtünme ve moleküllerin oryantasyonun, çekim oranının artmasıyla yükseldiği görülmüştür. Gupta ve El Mogazhy yaptıkları araştırmada, lifler arası sürtünme ve moleküler oryantasyon arasında önemli bir ilişki olduğunu bulmuşlar (Gupta, 2008).

Üçüncü özellik ise büküm sayısı olarak belirlenmiştir. Chattopadhyay ve Banerjee, 1996 yılında yaptıkları çalışmada; pamuk, rayon ve polyester ring ve rotor ipliklerinde bükümün artırılmasıly sürtünmenin düştüğünü bulmuşlardır. Yapılan çalışmada; yüksek büküm miktarının sıkıştırabilirliği düşürdüğü, sıkıştırabilirlik düştüğü için temas yüzeyinin de azaldığı temas yüzeyinin azalmasının ise sürtünme kuvvetini düşürdüğü tespitinde bulunmuşlardır. (Chattopadhyay ve S., 1996). Ghosh ve arkadaşlarının yaptığı diğer bir çalışmada; eğirme teknolojileri açısından, iplik yüzeyi geniş olan iplik-iplik sürtünmesini yüksek, iplik-metal sürtünmesinin düşük olacağı belirtilmiştir. (Ghosh, vd., 2008). Nishimatsu ve Savaki havlı (pile) kumaşların sürtünme özelliklerini, yapısındaki hav çözgü ipliklerinin büküm miktarındaki değişime çalışmada hav çözgü ipliklerinin büküm miktarının azalmasıyla kumaşın sürtünme dayanımının $\operatorname{arttığı~gözlemlenmiştir.~}$ Sürtünmenin tekstil endüstrisinde ne kadar önemli olduğu ortadadır. Sürtünmenin düzgünsüzlüğü nedeniyle ortaya çıkan problemlere çözüm bulmak adına yapılacak çalışmalardan öncellikle sürtünmeyi etkileyen faktörleri listelemesi beklenir. $\mathrm{Bu}$ çalışmada sürtünmeye etki eden faktörler veri madenciliği metoduyla incelenecektir.

Bilgisayar ve bilişim teknolojisinin gelişmesiyle birlikte bilgiye ulaşma yolları hem artmış hem de kolaylaşmıştır. Hayatın her alanında toplanan veriler yıllar içerisinde hızla artmaktadır. Bu verilerin toplanması ile birlikte toplandıktan sonra nasıl işleneceği ve nasıl depolanacağı da önemli bir sorun olarak karşımızda durmaktadır. Verilerin yorumlanıp gerekli bilgilerin açığa çıkarılması, birçok açıdan şirketlere ya da kurumlara önemli kazanımlar ve rekabet üstünlükleri sağlayacaktır. $\quad$ Veri madenciliğindeki temel amaç; veriler arasındaki ilişkilerin veya bağlantıların ortaya çıarılması ve verilerden çıkarılabilecek anlamlı bilgilerin analiz edilmesidir. Aynı zamanda veri madenciliği ile geleceğe dair tahmin ve planlar yapılırken çeşitli fikirler bilgisayar programları yardımıyla elde edilebilir.

Bilgisayar yardımıyla üretilen veriler işlenmeden ya da analiz edilmeden bir değer ifade etmezler. Ancak verilerin bilgilere dönüştürülmesiyle elde edilen veriler kullanıcılar açısından önem arz etmektedir 
(Kalikov, 2006). Verilerin işlenmiş haline belirsizlik ve muğlaklığın varlığında yeni bir

bilgi denir. İşlenmemiş verilerden yola karar verme yaklaşımıdır” diye çlkarak gelecek tahmininde bulunulması tanımlamıştır. Z. Pawlak tarafından 1982 mümkün değildir. Verilerden bilgi keşfinin yılında geliştirilen kaba kümeler teorisi gerçekleştirilmesi ve ileriye dönük evrendeki her nesnenin bazı bilgiler (veriler, tahminlerde bulunulması yöneticilere karar tecrübeler) ile birbirleriyle eşleştirilebileceği destek sağlayacaktır. Böylece ileride ortaya felsefesi üzerine kurulmuştur (Pawlak, 1997). çıkabilecek olumsuz bir durumun önlenmesi gerçekleştirilebilecektir (İnan, 2003). Büyük miktarda veri içeren veri kümelerinden bilgi keşfedilmesi işlemi oldukça önemlidir (Kalikov, 2006). Veri madenciliği uygulamaları ile büyük miktarda veri içeren veri setlerinden bilgi keşfetme süreçleri olarak tanımlanabilir (Thuarisingham, 2003).

Büyük miktardaki veri madenlerinden bilgi keşfetme çalışmalarında karşılaşılan önemli sorunlardan birisi veri içerisindeki eksik ya da hatalı bilgiler içeren verilerin varlığıdır. $\mathrm{Bu}$ hatalı verilerin işlenebilir hale getirilmesi için günümüze kadar çeşitli çalışmalar yapılmıştır. Bu konunun çözümü ve hatall, eksik ya da kesin olmayan verilerin analizi için 1982'de Pawlak tarafından geliştirilen "kaba kümeler" ve 1965 yllında Zadeh tarafından geliştirilen "bulanık kümeler" kullanılabilir (Zadeh, 1965; Pawlak, 1982). Bulanık kümeler, özellikle kimya alanında başarılı uygulamaları ile kullanım kazanmıştır. Bulanık ve kaba kümeler teorisinin ortak noktası, ilgilenilen veri kümesini ayırt edilemezlik ve muğlaklık noktasında incelemeleridir.

Z. Pawlak'ın yaptığı tanımda kaba küme teorisini kısaca "kaba küme teorisi $\mathrm{Bu}$ yaklaşım, yapay zekâ tekniklerinde karşılaşılan belirsiz veya şüpheli bilgilerle uğraşmakta kullanılmak üzere geliştirilmiş ve bilgi keşfinde karşılaşılan birçok problemin çözülmesine temel sağlamıştır (Yin, ve diğ., 2001). Kaba küme teorisi aynı zamanda uzaktan algılama (Pan, ve diğ., 2010), coğrafik bilgi bilimi (Leung, 2007), tıp (Thangavel, 2005), yapay zekâ (Tay ve Shen, 2003) ve duyarlılık haritalama (Aldridge, 1999) gibi birçok bilim disiplininde kullanılmıştır (Ling Peng vd., 2014).

$\mathrm{Bu}$ makale çalışmasında kaba kümeler teorisinin bir uygulaması geliştirilerek kaba kümeler teorisinin uygulama alanı genişletilmiştir. Kaba kümeler teorisi tekstil sektöründe uygulanarak muğlak verilerden avantajlı bilgiler elde edilmiştir. Çalışmada bahsedilen sürtünme, iki cismin birbirleriyle temas halindeyken birbirlerinin bağıl hareketine karşı gösterilen dirençtir. Sürtünme katsayısı ise iki obje arasındaki (iplik-iplik, iplikmetal, iplik-seramik vb.) sürtünme kuvvetinin iki objeyi birbirine bastıran kuvvete oranı olarak da belirtilebilir. $\mathrm{Bu}$ çalışmada sürtünmeden kaynaklanacak problemleri çözmek için ipliklerin sürtünme özelliklerine en çok etki eden iplik 
parametreleri araştırılmıştır. Yapılan terazi kullanılmıştır. Büküm ölçümleri için,

çalışmada ROSE 2 yazılımı kullanılmıştır.

\section{Materyal e Yöntem}

Çalışmada sekiz farklı tipte iplik kullanılmıştır. Seçilen ipliklerden her birinde beşer bobin test edilmiştir. Sürtünme deneylerine geçmeden önce ipliklerin yapısal özellikleri test edilmiştir. İplik numarası için sekiz bobinden birer adet ölçüm yapılarak iplik numaraları tespit edilmiştir. İplik numara ölçümlerinde iplik çırı̆̆g ve hassas her bobinden beşer adet ölçüm yapılarak ipliklerin bükümü hakkında bilgi edinmiştir. Büküm ölçümlerinde "Elle Çalışan Büküm Makinesi - Hand Driven Twist Tester" kullanılmıştır. Sürtünme ölçümlerinde Lawson Hamphil CTT iplik sürtünmesi testi cihazı kullanılarak lif-lif sürtünmesi ölçülmüştür. Deneyler 100 m/dk test hızıyla yapılmıştır. Üç farklı bağıl nem ortamında, iki farklı sürtünme yüzeyi kullanılarak ölçümler yapılmıştır.

Tablo 1. Bilgi sistemi

\begin{tabular}{|c|c|c|c|c|}
\hline & A1 & A2 & A3 & A4 \\
\hline & $\begin{array}{c}\text { Ort. Büküm } \\
\text { (T/inch) }\end{array}$ & $\begin{array}{c}\text { Üretim } \\
\text { Teknolojisi }\end{array}$ & Hammadde & $\begin{array}{c}\text { Iplik No } \\
(\mathrm{Ne})\end{array}$ \\
\hline X1 & 22 & Ring-Karde & Pamuk & 20 \\
\hline $\mathrm{X} 2$ & 21 & Ring-Penye & Pamuk & 30 \\
\hline X3 & 20 & OE-Karde & Pamuk & 30 \\
\hline $\mathrm{X4}$ & 22 & Ring & Pamuk/PES & 30 \\
\hline X5 & 22 & Ring & Viskon & 40 \\
\hline X6 & 21 & Ring & Lyocell & 30 \\
\hline $\mathbf{X 7}$ & 20 & Ring & Lyocell & 40 \\
\hline X8 & 20 & OE-Karde & Pamuk/PES & 30 \\
\hline X9 & 22 & Ring-Karde & Pamuk & 20 \\
\hline $\mathbf{X 1 0}$ & 21 & Ring-Penye & Pamuk & 30 \\
\hline
\end{tabular}

Ring, rotor ve friksiyon bükümlü ipliklerden dokunmuş kumaşların sürtünme özellikleri ve ring ipliklerden dokunmuş dimi kumaşların sürtünme özellikleri kumaş Kawabata Değerlendirme sistemi (KES_F: Kawabata's Evaluating Systemfor Fabrics) ile ölçülmüştür. Elde edilen MIU değerleri (kumaş ve çelik ağ arası sürtünme katsayısı); dokunmuş düz bez ayağı kumaşlarda en düşük olup, ardından ring kumaş, rotor kumaş ve ring dimi kumaş gelmektedir.

$\mathrm{Bu}$ çalışmada ipliklerin sürtünme özelliklerini etkileyen dört parametre ele alınmıştır. Bu özellikler; iplik numarası, üretim teknolojisi, ham madde ve iplik bükümüdür. On farklı örnek incelenmiş ve incelenme sonuçları Tablo 1'de verilmiştir (Nazarov ve Kamalov, 2010). 


\subsection{Kaba Kümeler Teorisi}

\subsubsection{Bilgi Sistemi}

Kaba kümeler teorisinde bilgi sistemi, evrensel küme (U), ve özellikler kümesi (A) olmak üzere 2 özellik kümesinden meydana gelir. Bu 2 özellikten oluşan kümeye bilgi sistemi adı verilir ve bu sistem Denklem 1'deki eşitliğe sahiptir. Bütün A özellikler bilgi sisteminde bir fonksiyon olarak tanımlanır (Walczak ve Massart, 1999) (Pawlak, 1998).

$$
\begin{aligned}
& \mathrm{IS}=(\mathrm{U}, \mathrm{A}) \\
& \mathrm{U}=\left\{\mathrm{x}_{1}, \mathrm{x}_{2}, \mathrm{x}_{3}, \ldots ., \mathrm{Xn}_{\mathrm{n}}\right\}
\end{aligned}
$$

Bilgi sistemine ait özelliklere karar sınıfının sisteme eklenmesi ile karar sistemleri oluşturulur. Bir karar sistemi $\mathrm{A}=(\mathrm{U}, \mathrm{A} \cup\{\mathrm{d}\}), \mathrm{d}^{\notin} \mathrm{A}$ şeklinde gösterilir. $\mathrm{Bu}$ yeni sistemde A özelliğinin elemanları koşul özellikleri ya da kısaca koşullar olarak adlandırılırlar (Komorowski, vd., 1998).

\subsubsection{Ayurt Edilemezlik İlişkisi}

Kaba kümeleme teorisinin temel noktalarından birisi ayırt edilemezlik ilişkisidir. Bu ilişki bazı nesneleri birbirinden ayırt edemediğimiz gerçeğine dayanır (Pawlak, 1982; Pawlak, 1997).

Bir karar tablosu bazen gereksiz genişlikte olabilir. $\mathrm{Bu}$ genişlikler bazı ayrılmazlık ilişkisi olan verilerin ya veri diğer bir değişle birbirinin aynısı olan verilerin tekrarı nedeniyle ortaya çıkar ya da bu tablo içerisinde gereksiz verilerden dolayı olabilir.

$\mathrm{Bu}$ durumda kullanılacak eşitlik notasyonları aşağıdaki gibidir.
$\mathrm{A}=(\mathrm{U}, \mathrm{A})$ olmak üzere her bir özellik seti için; B A için ayrılmazlık ilişkisi $\operatorname{IND}_{\mathrm{A}}(\mathrm{B})$ olarak gösterilir. Burada Ind (Indiscernibility Relation) yani ayırt edilemezlik ilişkisini verir.

A özellikler setindeki B alt özellikler seti için $\mathrm{B}\left(\mathrm{x}_{\mathrm{i}}\right)=\mathrm{B}\left(\mathrm{x}_{\mathrm{j}}\right)$ ise " $\mathrm{x}_{\mathrm{i}}$ ve $\mathrm{x}_{\mathrm{j}}$ nesneleri "ayırt edilemezdir" denir.

Nesnenin en küçük ayrılabilir gruplarını temsil ettiği için Ind(B), B özellikler kümesindeki temel set olarak adlandırılır. Temel setlerin elde edilmesi kaba küme teorisi kullanılarak yapılacak sinıflandırma işleminin ilk adımını oluşturur.

\subsubsection{Alt ve Üst Yaklașım Kümeleri}

$\mathrm{A}=(\mathrm{U}, \mathrm{A})$ bir bilgi sistemi olsun ve $\mathrm{B} \subseteq \mathrm{A}, \mathrm{X} \subseteq \mathrm{U}$ olsun. Bu durumda $\mathrm{X}$ kümesine üst yaklaşım ve alt yaklaşım kümeleri olmak üzere iki karşıt küme ile tanımlama yapabiliriz. Kaba Küme ile veri analizleri "alt yaklaşım” (lower approximation) ve "üst yaklaşım" (upper approximation) olmak üzere iki temel kavrama dayanır (Walczak ve Massart, 1999).

$\mathrm{X}$ setlerine ait alt yaklaşım kümesi $\mathrm{X}$ kümesinde kesinlik ihtiva eden tüm alt setlerin birleşimi olarak tanımlanır ve $\underline{B x}$ olarak gösterilir. Alt yaklaşım kümesindeki setler kesin olarak bir kümeye aittir. Bir alt kümenin alt yaklaşım kümesine ait olması eşitliği aşağıdaki şekilde ifade edilebilir.

$\underline{B x}=\{\mathrm{xi} \in \mathrm{U} \mid[\mathrm{xi}] \operatorname{Ind}(\mathrm{B}) \subset \mathrm{x}\}$ 
Üst yaklaşım kümesinin elemanları ise $\mathrm{X} \quad \mathrm{O}<\alpha \mathrm{B}(\mathrm{x}) \leq 1$

kümesindeki muhtemel üyelik olasılı̆̆ı olan elemanlardan oluşmaktadır. Üst yaklaşım kümesi $\overline{B x}$ şeklinde gösterilir ve aşağıdaki denklemdeki gibi ifade edilebilir.

$\overline{B x}=\{\mathrm{xi} \in \mathrm{U} \mid[\mathrm{xi}] \operatorname{Ind}(\mathrm{B}) \cap \mathrm{x} \not \subset \varnothing\}$

X kümesinin sınır elemanlarından oluşan küme ise sınır kümesidir. Sınır kümesi, $\mathrm{BN}(\mathrm{x})=\overline{B x}$ - $\underline{\mathrm{Bx}}$ şeklinde gösterilir.

Yaklaşım kümelerin özelliklerini şu şekilde gösterebiliriz.

$\underline{\mathrm{Bx}} \subseteq \mathrm{X} \subseteq \overline{\mathrm{Bx}}$

$\underline{\mathrm{Bx}}(\varnothing)=\overline{\mathrm{Bx}}(\varnothing)=\overline{\mathrm{Bx}}(\mathrm{U})=\mathrm{U}$

$\overline{\mathrm{Bx}}(\mathrm{X} \cup \mathrm{Y})=\overline{\mathrm{Bx}}(\mathrm{X}) \cup \overline{\mathrm{Bx}}(\mathrm{Y})$

$\underline{\mathrm{Bx}}(\mathrm{X} \cap \mathrm{Y})=\underline{\mathrm{Bx}}(\mathrm{X}) \cap \underline{\mathrm{Bx}}(\mathrm{Y})$

$\mathrm{X} \subseteq \mathrm{Y} \rightarrow \underline{\mathrm{Bx}}(\mathrm{X}) \subseteq \underline{\mathrm{Bx}}(\mathrm{Y})$ ve $\overline{\mathrm{Bx}}(\mathrm{X}) \subseteq \overline{\mathrm{Bx}}(\mathrm{Y})$

$\underline{\mathrm{Bx}}(\mathrm{X} \cup \mathrm{Y}) \supseteq \underline{\mathrm{Bx}}(\mathrm{X}) \cup \underline{\mathrm{Bx}}(\mathrm{Y})$

$\overline{\mathrm{Bx}}(\mathrm{X} \cap \mathrm{Y}) \subseteq \overline{\mathrm{Bx}}(\mathrm{X}) \cap \overline{\mathrm{Bx}}(\mathrm{Y})$

\subsubsection{Yaklaşımın Doğruluğu}

X kümesinin doğruluk ölçüsü aşağıdaki formül ile ifade edilir. Yani muğlaklık (vaguness) ve kabalık (roughness) sayısal olarak ifade edilebilir.

$\alpha(\mathrm{x})=\frac{\operatorname{card}(\underline{\mathrm{Bx})}}{\operatorname{card}(\overline{\overline{\mathrm{Bx}})}}$

$\operatorname{card}(B x):$ Alt yaklaşım kümesi eleman sayısı

$\operatorname{card}(\overline{B x})$ : Üst yaklaşım kümesi eleman sayisı $\alpha \mathrm{B}(\mathrm{x})=1 \rightarrow$ Kesin (Crisp) Küme

$\alpha \mathrm{B}(\mathrm{x})<1 \rightarrow$ Kaba Küme

\subsection{5. Özelliklerin Bağımsızhğı}

Özellikler kümesinin bağımlı olup olmadığını kontrol etmek için her bir özelliğin bilgi tablosundan sirayla silinmesi ile elde edilen temel setlerin sayısının artması ya da azalmasına bakılır.

$\operatorname{Ind}(\alpha)=\operatorname{Ind}\left(\alpha-\alpha_{\mathrm{j}}\right) \underset{\mathrm{a}}{\Rightarrow} \mathrm{a}^{\mathrm{j}}$ gereksizdir.

Ind $(\alpha) \neq$ Ind $\left(a-a_{j}\right) \underset{a}{\Rightarrow} a^{j}$ önemlidir, ihmal edilemez.

4) Gereksiz olan a özellikleri "D- Superflunus" olarak da adlandırılabilir.

\subsubsection{ROSE2 Yazhlim}

ROSE2, kaba küme teorisinin temel unsurlarının uygulanma ve kurallar bulmak için geliştirilmiş bir yazılımdır. Bu yazılım, Polonya'da, Poznan Teknik Üniversitesinde yazılmıştır. Bu yazılımda tüm hesaplamalar Pawlak tarafından geliştirilen Kaba Küme temellerine dayanmaktadır. ROSE2 yazılımının bazı özellikleri aşağıdaki gibidir (B.Predki, vd., 1998):

- Veri doğrulama

- Veri Ön işleme

- Özelliklerin ayrıştırılması

- Karar kuralları bulma

- Core ve Reduct kümelerini bulma

- Standart bir kaba küme temelli uygulamaları çalıştırma (Institute of Computing Science, 2014). 


\section{Bulgular ve Tartışma}

Kaba kümeler teorisinde bilgi sistemlerinden karar sistemlerini oluşturmak için koşul ve karar özelliklerinden oluşan yeni bir sistem oluşturulur. $\mathrm{Bu}$ sistem oluşturulurken kullanılacak olan ROSE2 yazılımının kullanımının kolaylaştırılması açısından veriler sayısallaştırılmış ve Kaba kümeler teorisi veri setlerine uygun halde Tablo 2'deki şekilde gösterilmiştir. Tablo 2'de 4 adet koşul özelliği ve 1 adet karar özelliği bulunmaktadır. Karar sınıfında yer alan "Yüksek/Orta/Düşük” seviyeleri iplik sınıfının sürtünme katsayısının seviyelerini göstermektedir. A1 özelliğindeki "Ortalama Büküm” değerleri sayısal veriler olduğu için aynı bırakılmış, A2, A3 ve A4 özellikleri ise sayısal değerler alacak şekilde güncellenmiştir. $\mathrm{Bu}$ güncellemede $\mathrm{A} 2$ sınıfi için 1 değeri Ring-Karde, 2 değeri RingPenye, 3 değeri OE-Karde, 4 değeri Ring sinıflarını belirtmektedir. A3 sinıfinda ise, 1 değeri Pamuk, 2 değeri Pamuk/PES, 3 değeri Viskon, 4 Değeri Lyocell hammadde sınıflarını belirtmektedir. A4 özellik kümesindeki sayısal değerler aynı şekilde bırakılmıştır. Oluşturulan yeni tablodan (Tablo 2) yola çıkılarak Kaba kümeler teorisi uygulaması gerçekleştirilecektir.

Bilgi tablosunu ROSE 2 yazılıminda çözdüğümüzde aşağıdaki gibi iki tane küme ve üç sınıf elde edilmiştir, bu bilgiler Tablo 3 'te verilmiştir. Sınıf sütunundaki $O, D$ ve $Y$ değerleri karar sınıfındaki Orta, Düşük ve Yüksek sınıflarını belirtmektedir. ROSE2 yazılımından elde edilen sonuç ile yapmış olduğumuz sınıflandırmanın kalitesi o,6 değeri çıkmıştır.
Tablo 2. Karar sistemi

\begin{tabular}{|c|c|c|c|c|c|}
\hline & $\mathrm{A}_{1}$ & $\mathrm{~A}_{2}$ & $\mathrm{~A}_{3}$ & $\mathrm{~A}_{4}$ & $\mathrm{D}$ \\
\hline $\mathbf{X}_{\mathbf{1}}$ & 22 & 1 & 1 & 20 & Yüksek \\
\hline $\mathbf{X}_{\mathbf{2}}$ & 21 & 2 & 1 & 30 & Orta \\
\hline $\mathbf{X}_{\mathbf{3}}$ & 20 & 3 & 1 & 30 & Düşük \\
\hline $\mathbf{X}_{\mathbf{4}}$ & 22 & 4 & 2 & 30 & Yüksek \\
\hline $\mathbf{X}_{\mathbf{5}}$ & 22 & 4 & 3 & 40 & Yüksek \\
\hline $\mathbf{X}_{\mathbf{6}}$ & 21 & 4 & 4 & 30 & Düşük \\
\hline $\mathbf{X}_{7}$ & 20 & 4 & 4 & 40 & Düşük \\
\hline $\mathbf{X}_{\mathbf{8}}$ & 20 & 3 & 2 & 30 & Yüksek \\
\hline $\mathbf{X}_{\mathbf{9}}$ & 22 & 1 & 1 & 20 & Orta \\
\hline $\mathbf{X}_{\mathbf{1 0}}$ & 21 & 2 & 1 & 30 & Yüksek \\
\hline
\end{tabular}

\subsection{Sinuflara Ayırma}

$\mathrm{Bu}$ değer sınıflandırmanın geçerli sayılabilmesi için yeterli olup aynı zamanda çalışmanın devam edebileceği hakkında bilgi vermektedir.

Tablo 3. Sinıflandırma ve kümeler

\begin{tabular}{|c|c|c|c|c|}
\hline Sınıf & $\begin{array}{c}\text { Nesne } \\
\text { Sayısı }\end{array}$ & $\begin{array}{c}\text { Üst } \\
\text { Yaklaşım }\end{array}$ & $\begin{array}{c}\text { Alt } \\
\text { Yaklaşım }\end{array}$ & Doğruluk \\
\hline O & 2 & o & 4 & o \\
\hline D & 3 & 3 & 3 & 1 \\
\hline Y & 5 & 3 & 7 & 0,42 \\
\hline $\begin{array}{c}\text { Sinıflama } \\
\text { Kalitesi }\end{array}$ & \multicolumn{5}{|c}{0,6} \\
\hline
\end{tabular}

\subsection{Core ve Reductların bulunması}

ROSE 2 yazılımını kullanarak bilgi tablosundan elde ettiğimiz Core ve Reduct'lar Tablo 4'teki gibidir. Çalışmada 2 adet reduct bulunmuştur. $\mathrm{Bu}$ reductlarda ortak olarak geçen A3 özelliği yapılan analizde core olarak belirlenmiştir. Core sınıfı bir veri setindeki en önemli özelliktir ve indirgenmesi kesinlikle düşünülemez. $\mathrm{Bu}$ çalışmada $A_{1}$ ve $A_{3}$ ya da $A_{2}$ ve $A_{3}$ özellikleri 
bir arada kullanılarak karar kurallarının adına konferanslar ve çalıştaylar çıkarılabileceği sonucunda ulaşılmıştır. düzenlenmektedir. Bu ilgi Kaba kümeler Üretilen reduct tablosu Tablo 4'te teorisinin uygulama alanlarını genişletmiş ve gösterilmiştir.

Tablo 4. Reduct tablosu

\begin{tabular}{|l|l|l|}
\hline No & Reduct & Nesne Sayıs1 \\
\hline $\mathbf{1}$ & $\mathrm{A}_{1}, \mathrm{~A}_{3}$ & $\mathbf{2}$ \\
\hline $\mathbf{2}$ & $\mathrm{A}_{2}, \mathrm{~A}_{3}$ & $\mathbf{2}$ \\
\hline
\end{tabular}

\subsection{Kurallarm Çıkarnlması}

Karar tablolarından üretilen karar kuralları Kaba kümeler teorisinin en önemli çıktısıdır. Oluşturulan karar sistemi verileri kullanılarak ROSE2 programının yardımı ile karar kuralları çıkarılmıştır. Bu adımda değişkenlere bağlı olarak karar vermek için kurallar geliştirilir. Bu çalışmada verileri ROSE 2'de çözdüğümüzde aşağıdaki kurallar elde edilir:

Kural 1: $\left(\mathrm{A}_{3}=4\right)=>(\mathrm{Dec}=\mathrm{D}) ;[2,2,66.67 \%$, 100.00\%][0, 2, o] Destekleyen Durumlar $(6,7)$

Kural 2: $\left(\mathrm{A}_{1}=20\right) \&\left(\mathrm{~A}_{3}=1\right)=>(\mathrm{Dec}=\mathrm{D})$; $[1,1,33.33 \%, 100.00 \%][0,1$, o] Destekleyen Durumlar (3)

Kural 3: $\left(\mathrm{A}_{3}\right.$ in $\left.\{2,3\}\right)=>(\operatorname{Dec}=\mathrm{Y}) ;[3,3$, $60.00 \%, \quad 100.00 \%][0,0,3][\{\},\{\}$, Destekleyen Durumlar $(4,5,8)$.

\section{Sonuç}

Kaba kümeler teorisi dünya çapında her geçen sene daha da fazla artan bir ilgiye sahiptir. Bu ilgiyi görebilmek için son yllarda bu konuda yayınlanan makale, bildiri, seminer ya da konferans sayllarma bakılabilir. Yine yakın zamanlarda bu konu her alanda kullanılabilir hale getirmiştir. Özellikle yapay zekâ uygulamalarında, makine öğrenmesinde, çlkarsamalarda, örgü algllamada ve bilgi keşfinde Kaba kümeler teorisi çok önemli bir yer edinmektedir. Bu makale çalışmasında da bu teorinin temel notasyonları ele alınarak sayısal bir örnekle çalışmanın sonuçları paylaşılmıştır.

Kaba kümeler teorisinin elimizdeki verilerde sonuca etkisi az olan belirtilerin yakalanıp çıkarılmasının önemi çok büyüktür. Bizim örneğimizde $\mathrm{A}_{4}$ özelliği (İplik numarası) sonuca etkisinin az olması nedeniyle kuralların çıkarılmasında ihmal edilmiştir. Elde edilen kuralların sözel yorumu aşağıdaki gibidir:

Kural 1: Eğer $\mathrm{A}_{3}=4$ ise ipliğin sürtünme katsayısı Düşük olur. Bu durumun ispatı için 6. ve 7. verilere bakılabilir.

Kural 2: Eğer $A_{1}=20$ ve $A 3=1$ ise ipliğin sürtünme katsayısı Düşük olur. Bu kuralın ispatı için 3. veriye bakılabilir.

Kural 3: Eğer $\mathrm{A}_{2}=2$ ya da $\mathrm{A}_{2}=3$ ise ipliğin sürtünme katsayısı Yüksek olur. $\mathrm{Bu}$ kuralın ispatı için $4,5,8$. verilere bakılır.

Buradan çıarılabilecek sonuç kuralları ile iplik özellikleri ile ilgili karar alıcılara destek sağlanabilir. Bunun yanı sıra çalışmada da belirtilen bir özelliğin ihmal edilmesi, veri madenciliğinin ve veri madenlerinden bilgi keşfinin önemli sonuçlarından birisidir. Yüksek veri kümelerinde sağlanacak bir özellik 
indirgemesi bilgi keşfinin zaman açısından önemli derecede kısalmasını sağlayacaktır. Özellik indirgeme yöntemi sayesinde üzerinde çalışılan veri setlerinin analizi daha kolay yapılabilmektedir. Ancak hangi özelliğin indirgeneceği konusu oldukça zor ve karmaşıtır. Gerekli olan bir bilginin kaybolması gibi bir durum söz konusu olabilir. Bu sorunların çözümü adına Kaba kümeler teorisinin avantajları mevcuttur. $\mathrm{A}_{4}$ özelliğinin özellik indirgenmesi sonucu hiçbir bilgi kaybının olmayacağı sonucuna ulaşılmıştır. $A_{3}$ özelliğinin ise bütün reduct sınıflarından geçmesinden dolayı indirgenemez temel bir özellik olduğu sonucuna varılmıştır. $A_{3}$ özellik kümesi iplik sürtünme katsayılarına etki eden en önemli özelliktir.

Sonuç olarak, bu çalışma ile birlikte tekstil endüstrisinde uygulaması çok az olan Kaba kümeler teorisinin bir uygulaması başarılı bir şekilde gerçekleştirilmiştir. Böylelikle Kaba kümeler teorisinin uygulama alanı genişletilmiş ve tekstil ürünleri imalatında çok önemli bir yere sahip olan iplik sürtünme özelliğine etki eden faktörler arasındaki ilişkiler incelenmiştir. Kaba kümeler teorisinin önemli özelliklerinden birisi de az ve belirsiz veriler ile çalışabilmesidir. Tekstil endüstrisinde kullanılan verilerin belirsizlik içermesi durumunda Kaba kümeler teorisi verilerin analizinde ve yorumlanmasında önemli bir fayda sağlayacaktır. Verilerden doğru bilgilerin çıkarılması çalışmalarında Kaba kümeler teorisinin karar kuralları

kullanılarak karar alıcıların işini

kolaylaştıracaktır.

\section{Kaynaklar}

Ajayi, J. ve Elder, H., 1994. Comparative Studies of Yarn and Fabric Friction. Journal of Testing and Evaluation, 463-467.

Aldridge, C. H., 1999. Discerning Landslide Hazard Using a Rough Set Based Geographic Knowledge Discovery Methodology. Otago: Citeseer.

B.Predki, ve diğerleri, 1998. ROSE - Software Implementation of the Rough Set Theory. Lecture Notes in Artificial Intelligence, 1424, 605-608.

Balcıl, G. ve Sülar, V., 2016. İpliklerde Sürtünme Özelliği: Önemi ve Ölçüm Yöntemleri. Tekstil ve Mühendis, 7374.

Chattopadhyay, R. ve S., B., 1996. The Frictional Behaviour of Ring-, Rotor-, and Friction-spun Yarn. Journal of Textile Institute, 59-67.

Denby, E. ve Andrews, M., 1965. Friction forces on wool fibers in a worsted fabric. Textile Research J., 913-922.

Ghosh, A., A., P., Anandjiwala, R. ve Rengasamy, R., 2008. A Study on Dynamic Friction of Different Spun Yarns. Journal of Applied Polymer Science, 3233-3238.

Gupta, B. S., 2008. Friction in textile materials. Boca Raton Boston New York Washington, DC: CRC Press. 
Hong, J., 2000. Structure-Process- Property

Relationships in Polyester Spun Yarns:

The Role of Fiber Friction. basim yeri

bilinmiyor:Georgia Institute of

Technology.

İnan, O., 2003. Veri madenciliği. Konya:

Selçuk Üniversitesi, Fen Bilimleri Enstitüsü.

Institute of Computing Science, P. U. o. T., 2014. Laboratory of Intelligent Decision Support Systems. http://idss.cs.put.poznan.pl/site/rose. html [21 01 2014].

Kalikov, A., 2006. Veri Madenciliği ve Bir ETicaret Uygulaması, Yüksek Lisans Tezi, basım yeri bilinmiyor: Gazi Üniversitesi, Fen Bilimleri Enstitüsü.

Kalyanaraman, A. R., 1988. Yarn-Friction Studies with the SITRA Friction Measuring Device. Journal of the Textile Institute, 147-151.

Komorowski, J., Polkowski, L. ve Skowron, A., 1998. Rough Sets: A Tutorial. 9 dü. Singapur: Springer-Verlag.

Leung, Y. F. T. M. J. W. W., 2007. A rough set approach to the discovery of classification rules in spatial data. International Journal of Geographical Information Science, 21, 1033-1058.

Ling Peng a, b. R. N. ve diğerleri, 2014. Landslide susceptibility mapping based on rough set theory and support vector machines: A case of the Three Gorges area, China. Geomorphology, 204, 287-301.
1976. Material science of Textile. basim yeri bilinmiyor:Vilnius: Mokslas.

Morton, W. E. ve Hearle, J. W., 1962. Physical properties of. The Textile Institute, 559-590.

Morton, W. E. ve Hearle, J. W., 1962. Physical properties of textile fibres. The Textile Institute, 559-590.

Nazarov, M. ve Kamalov, R., 2010. Farklı Bağıl Nem ve Sicaklık Koşullarında İplik Sürtünme Özelliklerinin İncelenmesi. Bitirme Ödevi, İzmir: Ege Üniversitesi, Mühendislik Fakültesi, (https://goo.gl/5SKLqj).

Pan, X. ve diğerleri, 2010. A variable precision rough set approach to the remote sensing land use/cover classification. 36 dü. Geosci: Comput.

Pawlak, Z., 1982. Rough Sets. International Journal of Computer and Information Sciences, 11, 341-356.

Pawlak, Z., 1997. Rough Set Approach to Knowledge-Based Decison Support. European Journal of Operational Research, 99, 48-57.

Pawlak, Z., 1997. Rough Sets Approach to Knowledge Based Decision Support. European Journal of Operational Research, 99, 48-57.

Pawlak, Z., 1998. Rough Set Theory And Its Applications To Data Analysis. Cybernetics and Systems: An International Journal, 29(7), 661-668. 
Pažarauskas, E., 1992. Prediction of Friction Properties of New Threads According up Today Technologies. - PhD Thesis, p. 191.

Rankumar, S. ve diğerleri, 2003. Experimental Study of the Frictional Properties of Friction Spun Yarns. Journal of Applied Polymer Science, 2450-2454.

Schick, M., 1973. Friction and Lubrication of Synthetic Fibers. Textile Research Journal, 198-204.

Svetnickienè, V. ve Čiukas, R., 2006. Technical and classical yarns friction properties investigation. Mechanika, 4(60), 54-58.

Svetnickienè, V. ve Čiukas, R., 2006. Technical and Classical Yarns Friction Properties Investigation. Mechanika, 54-58.

Tay, F. ve Shen, L., 2003. Fault diagnosis based on rough set theory. Engineering Applications of Artificial Intelligence, $16,39-43$.

Thangavel, K. J. P. P. A. K. M., 2005. Effective classification with improved quick reduct for medical database using rough system. Bioinforma. Med. Eng., 5, 7-14.

Thuarisingham, B., 2003. Web Data Mining and Applications in Business Intelligence and Counter Terrorism. Boca Raton: CRC Press LLC.

Varža, V., 1981. Manufacturing of WoolPolyester Yarns, Having Different
Structure and Investigation of Them Properties.Kaunas.

Walczak, B. ve Massart, D., 1999. Rough sets theory. Chemometrics and Intelligent, 47, 1-16.

Walczak, B. ve Massart, D., 1999. Rough sets theory. Chemometrics and Intelligent Laboratory Systems, 47, 1-16.

Wegener, W. ve Shuler, B., 1964. Determination of the friction coefficient. Textilindustrie, 458-463.

Yin, X., Zhou, Z., Li, N. ve Chen, S., 2001. An Approach for Data Filtering Based on. Berlin: Springer-Verlag.

Zadeh, L. A., 1965. Fuzzy sets. Information Control, 338-353. 